\title{
Medical Branch Choice in Turkey and Beneficience
}

\author{
Karatas $\mathbf{M}^{1}$, Burak Selcuk E2 ${ }^{2}$ Karatas $\mathrm{T}^{3}$ and Zirhli Selcuk $\mathrm{S}^{4}$ \\ ${ }^{1}$ Inonu University Faculty of Medicine, Dept. of History of Medicine and Ethics, Malatya, \\ Turkey
}

${ }^{2}$ Inonu University Faculty of Medicine, Dept. of Family Medicine, Malatya, Turkey

${ }^{3}$ Malatya Training Research Hospital, General Surgery, Malatya, Turkey

${ }^{4}$ Malatya Training Research Hospital, Pediatrics, Malatya, Turkey

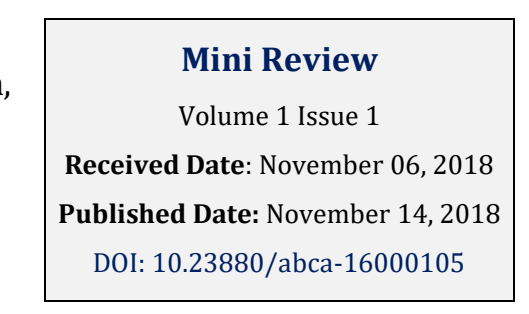

*Corresponding author: Mehmet Karatas, Inonu University Faculty of Medicine, Dept. of History of Medicine and Ethics, Malatya,Turkey, Email: drkaratas@hotmail.com

\section{Abstract}

Medical school trainings are provided to enable medical students to benefit their patients in their professional lives. When looking at occupational branch preferences, it is seen that the physicians are in a position to protect themselves by choosing less risky areas in Turkey.

The situation will be clear when examining the preferences of first-time entrants by the TUS (Medical Specialty Exam) from 2015 for problem determination in Turkey. Empty staff have been in branches such as Internal Medicine, Pediatrics, General Surgery, Pediatric Surgery, Thoracic Surgery, Cardiovascular Surgery, Neurosurgery, Obstetrics and Gynecology. The more preferred branches are Dermatology, Ophtalmology, Radiology, Physical Therapy.

This finding suggests that there may be physician distress, especially in some clinical settings in the coming years. It is seen that in the preferences of the physicians in the past periods, the financial gain is the preliminary plan, nowadays, the possibility of the medical error is less, the less contact with the judicial processes, and the worry of allocating more time to himself and his family in daily life.

Although this situation seems to be useful and logical for the physician right now, the fact that heavy surgery and major branches are not preferred especially for advanced specialization suggests that these branches will be empty and lead to the problem of medicine accessibility for future generations in these branches in Turkey.

Keywords: Physicians; Branch choice; Beneficience

\section{Introduction}

People have always had a tendency to be comfortable and easy. Many changes and transformations in the field of medicine have been experienced in this sense. Nowadays, it is possible to see such a change very clearly when we look at the branches of physicians in medical applications. 
Human has, by his nature, the tendency and the willingness to perform his / her profession in an environment which has low workload, little forensic processes, appropriate conditions, professional dignity and good salary. In order to become a physician, it is necessary to have a good score in the university exam in our country and to complete the medical education which will last for six years. Having graduated from medical school means that you are still on the road halfway through our country. Because it tend to specialize in Turkey is quite high.

Another phase of the professional development process is preferred by choosing any of the specialties. At this point, particularly in Turkey made TUS (Medical Specialization Examination) candidates in the choice of specialized physicians makes it possible to see what the trend is.

When examining the preferences of those entering the first 100 with the Medical Specialist Exam starting in 2015, the situation will be seen clearly. The vacancies have been in the branches such as Internal Medicine, Pediatrics, General Surgery, Pediatric Surgery, Thoracic Surgery, Cardiovascular Surgery, Neurosurgery, Gynecology and Obstetrics. More preferred branches were Dermatology, Ophtalmology, Radiology, Physical Therapy $[1,2]$.

\section{Root Cause}

It is clear that those who consciously choose medicine, which is a discipline that requires a lot of dedication, effort, sacrifice and courage, are the people who are trying to be beneficial to people.

The usefulness of basic ethical principles is an inevitable necessity of the profession [3]. The physicians who will fulfill this requirement also have a hard education and professional life. In the course of the practice of the medical profession, preferences may be somewhat of a feature when they encounter a process that they should prefer to be more useful to their patients, such as TUS.

Particularly the main branch conditions in Turkey, Internal Medicine, Pediatrics, Obstetrics and Gynecology, General Surgery, Neurosurgery training in specialties or getting to work to provide healthcare processes are known to be quite difficult. This situation is clearly seen when compared with Dermatology, Ophthalmology, Radiology and Physical Therapy branches.
Comfortable branches are preferred in specialist training process where no excessive patients, no many shifts. Perhaps the most important point is the branches where there is not much contact with the patient.

The fact that salaries are the same as the other difficult branches and that there is no great difference in the perquisite payments is also effective. However, even if the case of much the perquisite payments, physicians' difficult branches are not still preferred by TUS.

The fact that the possibility of medical error is low, being less interested in forensic processes, and more time for him and his family to spend more time, lead to preferences.

It is seen that the areas where less risk is taken are preferred by the physician. The examination of the preferences of those entering the first 100 with the TUS starting in 2015 will be seen clearly (Table 1).

\begin{tabular}{|c|c|}
\hline Branches & n \\
\hline Dermatology & 23 \\
\hline Ophtalmology & 18 \\
\hline Radiology & 16 \\
\hline Physical therapy & 12 \\
\hline Child Psychiatry & 7 \\
\hline Plastic, Reconstructive and Aesthetic Surgery & 7 \\
\hline Psychiatry & 3 \\
\hline Otorhinolaryngology & 3 \\
\hline Internal Medicine & 3 \\
\hline Cardiology & 2 \\
\hline Radiation oncology & 2 \\
\hline Pediatrics & 1 \\
\hline Medical Genetics & 1 \\
\hline Neurosurgery & 1 \\
\hline Orthopedics and Traumatology & 1 \\
\hline Pediatric Surgery & - \\
\hline General Surgery & - \\
\hline Thoracic Surgery & - \\
\hline Cardiovascular Surgery & - \\
\hline Gynecology and Obstetrics & - \\
\hline Total & $\mathbf{1 0 0}$ \\
\hline
\end{tabular}

Table 1: The most preferred branches of the first 100in the 2015 spring TUS.

The most preferred branches of the first 100 in the autumn of the same year (2015); Radiology (24 people), Ophtalmology (20 people), Dermatology (17 people), Physical Therapy (8 people). General Surgery, Pediatric 
Surgery, Thoracic Surgery, Neurosurgery and Obstetrics and Gynecology branches were not preferred [1,2].

Compulsory Medical Liability Insurance for Medical Malpractice has been made by the physicians since its publication in the Resmi Gazete. In the extreme risk grouping in this Communique, we especially see branches in risk groups 3 and 4 (Table 2) [4,5].

\begin{tabular}{|c|c|c|c|c|}
\hline & \multicolumn{4}{|c|}{ Risk ratio } \\
\hline Branches & 1 & 2 & & \\
\hline Emergency Medicine & & & & \\
\hline Anesthesiology and Reanimation & & & & \\
\hline Neurosurgery & & & & $\underline{x}$ \\
\hline General Surgery & & & & \\
\hline Thoracic Surgery & & & & \\
\hline Gynecology and Obstetrics & & & & \\
\hline Cardiovascular Surgery & & & & \\
\hline Orthopedics and Traumatology & & & & \\
\hline Plastic, Reconstructive and Aesthetic Surgery & & & & $\mathrm{x}$ \\
\hline
\end{tabular}

Table 2: Some branches in the high risk group. (1: lowest, 4: highest).

When the content of this table is examined, it is seen that the branches in the risk group are not preferred especially in TUS. It is seen that people who are doing medicine tend to be away from risk and to spend more time on their own family.

\section{Conclusion}

It can be considered a natural process for the physician to choose a branch where the process of education is easy, the probability of medical error is low, it is less addressed by judicial processes and it can give time to his / her family. These preferences can be considered innocent if they are made with the idea of being more useful in their profession. However, if such a preference process is experienced with the thought or effort of a physician to escape from human beings, the subject should be examined sociologically, psychologically and ethically.

It is possible to say that especially the heavy surgical branches that require advanced expertise are left empty, the main branches are not preferred, the physician will be able to reach the physician in these branches for future generations and the physician may prefer to have less problems by trying to move away from the patient. In order not to have access to health services from basic human rights, this issue should be evaluated by the interlocutors [6-10].

\section{Conflicts of Interest: None.}

Acknowledgement: This study was orally presented at Turkey Bioethics Society IX National Congress in 9-12 May 2018 in Mersin (Turkey).

\section{References}

1. Batı F. Which branches preferred of the first 100 in TUS! Here are the most popular branches.

2. Öztürk A. Great change preferences in TUS! Here are the most popular branches

3. Beauchamp TL (1989) Childress JF Principles of Biomedical Ethics. $3^{\text {rd }}$ (Edn.), Oxford University.

4. Physician Liability Insurance.

5. (2010) Communique on Procedures and Principles Regarding the Institution Contribution to Compulsory Liability Insurance for Medical Malpractice. Resmi Gazete.

6. Patients' Rights Regulation. (1998) Resmi Gazete. Sayı: 23420 .

7. Arda B (2003) International Documents on Medicine and Health. Ed. Erdemir AD, Öncel Ö, Aksoy Ş. Çağdaş Tıp Etiği. Nob Tıp Kitab 53-85.

8. Patients' Rights (1981) World Medical Association Patients' Rights Declaration. Lizbon.

9. Patients' Rights (1994) European Improvement of Patients' Rights. Amsterdam.

10. Universal Declaration of Human Rights (1948) United Nation General Assembly. 